\title{
Factors Associated With Reoperation After Fixation of Displaced Olecranon Fractures
}

\author{
Femke M. A. P. Claessen MD, Yvonne Braun MD, Rinne M. Peters BSc, \\ George Dyer MD, Job N. Doornberg MD, PhD, David Ring MD, PhD
}

Received: 5 April 2015/Accepted: 29 July 2015/Published online: 7 August 2015

(C) The Association of Bone and Joint Surgeons $\mathbb{R} 2015$

\begin{abstract}
Background Surgery for fixation of olecranon fractures is associated with reoperation, mostly for implant removal. A study of a large cohort of patients treated by many different surgeons allows us to determine if specific techniques or implants are associated with a higher rate of reoperation.

Questions/purposes After open reduction and internal fixation of isolated olecranon fractures, what factors are associated with (1) reoperation and (2) implant removal? Methods Three hundred ninety-two adult patients who had operative treatment of a displaced olecranon fracture not associated with other fractures, dislocation, or subluxation at two area hospitals between January 2002 and May
\end{abstract}

One of the authors (DR) received grants from Skeletal Dynamics (Miami, FL, USA) in the amount of USD 10,000 to USD 100,000, other from Wright Medical (Memphis, TN, USA) in the amount of less than USD 10,000, personal fees from Biomet (Warsaw, IN, USA) in the amount of less than USD 10,000, personal fees from Acumed (Hillsboro, OR, USA) in the amount of less than USD 10,000), other from IlluminOss Medical, Inc (East Providence, RI, USA; stock options only), personal fees as Deputy Editor for the Journal of Hand Surgery (less than USD 10,000), personal fees as Deputy Editor for Clinical Orthopaedics and Related Research ${ }^{\circledR}$ (less than USD 10,000), personal fees from universities and hospitals (less than USD 10,000), and personal fees from lawyers (less than USD 10,000) outside the submitted work.

All ICMJE Conflict of Interest Forms for authors and Clinical Orthopaedics and Related Research ${ }^{\circledR}$ editors and board members are on file with the publication and can be viewed on request.

Clinical Orthopaedics and Related Research ${ }^{\mathbb{R}}$ neither advocates nor endorses the use of any treatment, drug, or device. Readers are encouraged to always seek additional information, including FDAapproval status, of any drug or device prior to clinical use.

Each author certifies that his or her institution approved the human protocol for this investigation, that all investigations were conducted in conformity with ethical principles of research, and that informed consent for participation in the study was obtained.
2014 were analyzed to determine factors associated with reoperation. One hundred thirty-eight $(35 \%)$ patients had plate and screw fixation and $254(65 \%)$ tension band wiring. Nearly $100 \%$ of patients with displaced olecranon fractures are currently treated operatively at our hospitals. All patients were followed for at least four months. Two hundred three of the $392(52 \%)$ patients were followed for one year or more. Ninety-nine patients (25\%) had a second operation, $92(93 \%)$ at least in part for implant removal (12 for wire migration [3\% of all fractures, $12 \%$ of reoperations]). We considered patient-related, fracture-related, and implant-related endpoints as possible factors associated with reoperation. With a total sample size of 99 reoperations, an $\alpha$ of 0.05 , and an effect size of 0.3 , we had $87 \%$ power.

This work was performed at Massachusetts General Hospital-Harvard Medical School, Boston, MA, USA.

Electronic supplementary material The online version of this article (doi:10.1007/s11999-015-4488-2) contains supplementary material, which is available to authorized users.

F. M. A. P. Claessen, Y. Braun, R. M. Peters, D. Ring Massachusetts General Hospital, Hand Surgery, Boston, MA, USA

G. Dyer

Upper Extremity Division, Department of Orthopaedic Surgery, Brigham Women's Hospital, Boston, MA, USA

\section{J. N. Doornberg}

Orthotrauma Research Center Amsterdam, University of Amsterdam Orthopaedic Residency Program (PGY 6), Amsterdam, The Netherlands

D. Ring $(\bowtie)$

Orthopaedic Surgery, Harvard Medical School, Yawkey Center,

Suite 2100, 55 Fruit Street, Boston, MA 02114, USA

e-mail: dring@mgh.harvard.edu; dring@partners.org 
Results Reoperation was less common in men (36 [36\%], women: 63 [64\%]; adjusted odds ratio, 0.32; 95\% confidence interval, $0.18-0.56 ; \mathrm{p}<0.001$ ) and older patients (adjusted odds ratio, 0.75; 95\% confidence interval, 0.65$0.87 ; \mathrm{p}<0.001)$. Similarly, request for implant removal was less in men (33 [36\%], women: 59 [64\%], adjusted odds ratio, 0.31 ; $95 \%$ confidence interval, $0.18-0.56$; $\mathrm{p}<$ 0.001 ) and older patients (adjusted odds ratio, 0.75; 95\% confidence interval, 0.65-0.87; $\mathrm{p}<0.001$ ).

Conclusions Patients who have operative fixation of a fracture of the olecranon can be counseled that most patients keep their implants, that only 3\% experience implant migration, and that technical factors such as the type or configuration of an implant seem less important than personal factors in determining who requests a second surgery for implant removal.

Level of Evidence Level III, prognostic study.

\section{Introduction}

Operative fixation of displaced olecranon fractures achieves union and excellent elbow function but is associated with reoperation, usually for implant removal [8, 20, 21]. A substantial rate of second surgeries to remove tension band wires led orthopaedic surgeons to consider alternatives such as plate fixation [14] or intramedullary screws or rods [13] for olecranon fractures [3, 7]. On the other hand, it is estimated that the total costs-even after reoperation-are much lower for tension band wires than for plate fixation [13] and it is not clear that plates (which are also prominent) cause fewer symptoms.

Attempts to decrease reoperation for implant removal have focused on techniques for decreasing the prominence and tendency for migration of tension band wires and the development of lower profile plates and intramedullary implants $[1-7,10-14,17,18,20]$. Saeed and colleagues [20] studied 182 patients and found that older age, bent wires, medullary/transcortical wire positioning, proximal prominence, ulnar shaft angle, distance from the articular surface, and articular step were associated with wire migration after tension band wire fixation of a displaced fracture of the olecranon.

Our observation is that all implants on the olecranon are somewhat prominent and that requests for removal of implants may relate more to personal than to technical factors. Patient-related factors associated with reoperation and implant removal after open reduction and internal fixation of isolated olecranon fractures are not well studied.

After open reduction and internal fixation of isolated displaced olecranon fractures, what factors are associated with (1) reoperation and (2) implant removal?

\section{Material and Methods}

This retrospective study was approved by our institutional review board. We identified 625 patients who had open reduction and internal fixation of an isolated displaced olecranon fracture (Mayo Type 2A or 2B) that was not part of a fracture-dislocation between January 2002 and May 2014 using the institutions' Research Patient Data Registry (RPDR) database covering all surgeries at two Level I trauma centers: 418 patients treated at one and 207 at the other. Current Procedural Terminology (CPT) procedure codes for proximal ulna fracture were used to identify patients who had operative treatment of an olecranon fracture (Appendix 1 [Supplemental materials are available with the online version of $\left.\mathrm{CORR}^{\circledR}{ }^{\circledR}\right]$ ). Medical record data, International Classification of Diseases, $9^{\text {th }}$ Revision code (ICD-9), demographic information (such as, gender, date of birth, and race), and operative and radiology reports of patients with this CPT code were retrieved through the institutional RPDR. For patients who had more than one olecranon fracture surgery, we tracked the first surgery as the index procedure.

We excluded (1) patients younger than 18 years of age $(\mathrm{n}=24)$; (2) patients with prior surgery elsewhere $(\mathrm{n}=11)$; and (3) miscoded patients with no olecranon fracture $(\mathrm{n}=$ 52). After reviewing the radiographs, we excluded (4) patients with an olecranon fracture-dislocation (Mayo Type 3) $(\mathrm{n}=91)$; (5) patients with a concomitant distal humerus fracture $(\mathrm{n}=8)$; (6) patients with multiple elbow fractures $(\mathrm{n}=41)$; and (7) patients with Mayo Type 1 (nondisplaced) olecranon fractures $(n=6)$. The final cohort included 392 patients with an isolated Mayo 2A or 2B (displaced without instability) fracture of the olecranon: 138 patients treated with plate and screw fixation and 254 with tension band wiring. All patients were followed for at least four months. Two hundred three of the $392(52 \%)$ patients were followed for one year or more.

The vast majority of patients with displaced fractures of the olecranon were treated with open reduction and internal fixation at these hospitals during the study period. The choice and configuration of the implants were at the surgeon's discretion. All surgeons used both techniques for fixation of a simple olecranon fracture.

We reviewed the medical records of all patients for our primary outcome variables: reoperation and implant removal. In total, 99 patients underwent reoperation. Reasons included prominent hardware $(n=69)$, infection $(n=$ 15), elbow release for contracture $(n=5)$, ulnar nerve release $(n=5)$, failure of fixation $(n=4)$, and nonunion of irradiated bone without fixation failure $(n=1)$. Five patients had a second surgery for incision and drainage for infection without implant removal, and two patients had reoperation 
for ulnar nerve release without implant removal. We only considered the first reoperation in the calculations.

Among the 92 patients who had implant removal, 69 were for implant prominence $(75 \%)$ and 23 were at the time of another surgical procedure. Seven patients who had a prominent migrated wire removed in the office under local anesthesia were counted as second procedures. Twentyseven patients with plate and screw fixation and 42 patients with tension band wiring requested implant removal for implant prominence. Wire migration was described in 12 patients as contributing to implant prominence. In the other 57 cases no reason for implant prominence was mentioned. Twelve implant removals were for tension band wire migration representing $3 \%$ of all fractures, $4.7 \%$ of all tension band wirings, and $12 \%$ of all reoperations.

Ninety-nine of 392 fractures $(25 \%)$ had a second operation, $92(93 \%)$ at least in part for implant removal (56 of 254 [22\%] after tension band wiring; 36 of 138 [26\%] after plate and screw fixation). Sixty-nine patients (18\% of the total and $75 \%$ of all reoperations) had reoperations specifically for dissatisfaction with or loosening or breakage of the implants (42 of 254 [16\%] after tension band wiring; 27 of 138 [20\%] after plate and screw fixation).

ICD-9 codes and text search were used (Appendix 2 [Supplemental materials are available with the online version of $\mathrm{CORR}^{\circledR}$.]) to search for the explanatory variables used in our bivariate analysis. We included the following explanatory variables: age at operative treatment, gender, race, obesity, head injury, Charlson Comorbidity Index (CCI) [19], smoking, duration of surgery, open fracture, other fracture of the same limb, other fractures elsewhere, surgeon, surgeon experience in years since graduation from residency, hospital, and type of implant (plate versus tension band wire). We only analyzed head injuries as a risk factor if they occurred at the same time as the olecranon fracture.

We also reviewed radiographs and included the following explanatory variables to our bivariate analysis: comminution (Type 2B versus Type 2A) [16], Kirschner wires parallel (yes/no), Kirschner wire size (0.045 inch versus 0.062 inch or metric equivalent), Kirschner wires angled anteriorly to engage anterior cortex or straight intramedullary (yes/no), Kirschner wires turned at least $150^{\circ}$ and impacted into the proximal ulna (yes/no), tension wire (size: 16- or 18- and 20- or 22-gauge wire), single or double tension wire, one knot or two in each tension wire, plate length ( $\mathrm{cm}$ distal to the fracture), and plate type.

\section{Statistical Analysis}

Normality of our continuous data was tested using the Shapiro-Wilk test. The difference in explanatory variables among failure of fixation and implant removal was assessed using a Fisher's exact test for dichotomous and categorical variables and an unpaired t-test for continuous variables. Variables were presented with frequencies and percentages for categorical variables and as mean with SD for continuous variables.

Factors with $\mathrm{p}<0.10$ in bivariate analysis were entered into a multivariable logistic regression analysis to assess if possible risk factors were independently associated with failure of fixation and implant removal. A two-sided $\mathrm{p}$ value $<0.05$ was considered to indicate statistical significance. With a total sample size of 99 reoperations, an $\alpha$ of 0.05 , and an effect size of 0.3 , we had $87 \%$ power.

\section{Results}

After controlling for potentially relevant confounding variables in multivariable analysis, we found that women and younger patients were more likely to undergo a reoperation (Table 1). For gender, men (36 [36\%]) were less likely to request implant removal than women (63 [64\%]) (adjusted odds ratio [OR], 0.32; 95\% confidence interval [CI], 0.18-0.56; p < 0.001). Analysis of age per decade demonstrated that younger age is associated with reoperation (adjusted OR, 0.75; 95\% CI, 0.65-0.87; p < 0.001). Initial bivariate analysis revealed younger age, lower CCI, and gender to be associated factors (Table 2).

Similarly after controlling for potentially relevant confounding variables, request for implant removal was less in men (33 [36\%], women: 59 [64\%]; adjusted OR, 0.31; 95\% CI, 0.18-0.56; $\mathrm{p}<0.001$ ) and older patients (adjusted OR, 0.75; 95\% CI, 0.65-0.87; p < 0.001) (Table 3).

Initial bivariate analysis revealed younger age, lower CCI, injury side, and gender to be associated factors (Table 4).

\section{Discussion}

Reoperation is common after surgery for internal fixation of olecranon fractures. Most of these are the result of implant removal. Saeed and colleagues [20] found several surgically modifiable factors related to spontaneous wire

Table 1. Multivariable analysis-factors associated with reoperation $(\mathrm{n}=392)$

\begin{tabular}{lllr}
\hline Parameter & $\begin{array}{l}\text { Adjusted } \\
\text { odds ratio }\end{array}$ & $\begin{array}{l}\text { Adjusted 95\% } \\
\text { confidence interval }\end{array}$ & $\begin{array}{l}\text { Adjusted } \\
\text { p value }\end{array}$ \\
\hline Age per 10 years & 0.75 & $0.65-0.87$ & $<0.001$ \\
$\begin{array}{l}\text { Charlson Comorbidity } \\
\quad \text { Index }\end{array}$ & 0.91 & $0.78-1.0$ & 0.186 \\
$\begin{array}{l}\text { Gender } \\
\text { Injury side }\end{array}$ & 0.32 & $0.18-0.56$ & $<0.001$ \\
\hline
\end{tabular}


Table 2. Bivariate analyses-factors associated with reoperation $(n=392)$

\begin{tabular}{|c|c|c|c|c|}
\hline \multirow[t]{2}{*}{ Parameter } & \multicolumn{2}{|c|}{ Reoperation $(\mathrm{n}=99[25 \%])$} & \multirow[b]{2}{*}{$\begin{array}{l}\text { Odds ratio } \\
\text { (CI) }\end{array}$} & \multirow[t]{2}{*}{$\mathrm{p}$ value } \\
\hline & $\begin{array}{l}\text { Yes } \\
\text { Mean (SD) }\end{array}$ & $\begin{array}{l}\text { No } \\
\text { Mean (SD) }\end{array}$ & & \\
\hline Age (years) & $50(18)$ & $58(20)$ & $0.98(0.97-0.99)$ & $<0.001$ \\
\hline Charlson Comorbidity Index & $0.70(1.7)$ & $1.4(2.3)$ & $0.83(0.72-0.96)$ & 0.011 \\
\hline Experience surgeon (years) & $11(8.5)$ & $10(8.5)$ & $1.1(0.98-1.0)$ & 0.79 \\
\hline Duration (hours) & $1.3(1.5)$ & $1.4(1.2)$ & $0.93(0.73-1.2)$ & 0.59 \\
\hline \multirow[t]{2}{*}{ Plate length ( $\mathrm{cm}$ distal to fracture) } & $6.2(1.4)$ & $6.5(1.9)$ & $0.90(0.71-1.1)$ & 0.39 \\
\hline & Number $(\%)$ & Number $(\%)$ & Odds ratio $(\mathrm{CI})$ & $\mathrm{p}$ value \\
\hline Gender & & & $0.58(0.36-0.92)$ & 0.027 \\
\hline Men & $36(36)$ & $146(50)$ & & \\
\hline Women & $63(63)$ & $147(50)$ & & \\
\hline Diagnosed obesity & & & $1.3(0.57-2.9)$ & 0.52 \\
\hline Yes & $9(9)$ & $21(7)$ & & \\
\hline No & $90(91)$ & $272(93)$ & & \\
\hline Smoking* & & & $1.3(0.72-2.4)$ & 0.43 \\
\hline Yes & 19 (19) & $45(15)$ & & \\
\hline No & $80(81)$ & $248(85)$ & & \\
\hline Head injury & & & $0.73(0.27-2.0)$ & 0.64 \\
\hline Yes & $5(5)$ & $20(7)$ & & \\
\hline No & $94(95)$ & $273(93)$ & & \\
\hline Open fracture & & & $1.5(0.69-3.4)$ & 0.28 \\
\hline Yes & $10(10)$ & $20(7)$ & & \\
\hline No & $89(9)$ & $273(93)$ & & \\
\hline Other fracture & & & $0.83(0.39-1.7)$ & 0.72 \\
\hline Yes & $10(10)$ & $35(12)$ & & \\
\hline No & $89(90)$ & $258(88)$ & & \\
\hline Other fracture same limb & & & $0.49(0.20-1.2)$ & 0.13 \\
\hline Yes & $6(6)$ & $34(12)$ & & \\
\hline No & $93(94)$ & $259(88)$ & & \\
\hline Hospital & & & $1.4(0.84-2.2)$ & 0.21 \\
\hline Hospital 1 & $65(66)$ & $212(72)$ & & \\
\hline Hospital 2 & $34(34)$ & $81(28)$ & & \\
\hline Fracture type & & & $1.2(0.78-2.0)$ & 0.41 \\
\hline Mayo 2A & $54(55)$ & $174(60)$ & & \\
\hline Mayo 2B & $45(45)$ & $117(40)$ & & \\
\hline Figure of eight & & & $0.88(0.55-1.4)$ & 0.63 \\
\hline Yes & $62(63)$ & $192(66)$ & & \\
\hline No & $37(37)$ & $101(34)$ & & \\
\hline Plate fixation & & & $0.96(0.55-1.7)$ & 0.63 \\
\hline Yes & $37(37)$ & $101(34)$ & & \\
\hline No & $62(63)$ & $192(66)$ & & \\
\hline Kirschner wires parallel & & & $1.1(0.57-2.2)$ & 0.73 \\
\hline Yes & $16(30)$ & $42(28)$ & & \\
\hline No & $37(70)$ & $110(72)$ & & \\
\hline Size of Kirschner wires & & & $1.2(0.58-2.4)$ & 0.73 \\
\hline 0.045 inch & $13(23)$ & $44(26)$ & & \\
\hline 0.062 inch & $44(77)$ & $127(74)$ & & \\
\hline
\end{tabular}


Table 2. continued

\begin{tabular}{|c|c|c|c|c|}
\hline & Number $(\%)$ & Number $(\%)$ & Odds ratio $(\mathrm{CI})$ & $\mathrm{p}$ value \\
\hline Angle Kirschner wires & & & $0.92(0.43-1.9)$ & 1.0 \\
\hline $\begin{array}{l}\text { Anteriorly to engage anterior } \\
\text { cortex }\end{array}$ & $36(75)$ & $110(73)$ & & \\
\hline Straight intramedullary & $12(25)$ & $40(27)$ & & \\
\hline $\begin{array}{l}\text { Kirschner wire turned } 150^{\circ} \text { and } \\
\text { impacted into the proximal ulna }\end{array}$ & & & $1.2(0.66-2.4)$ & 0.52 \\
\hline Yes & $31(62)$ & $88(59)$ & & \\
\hline No & $18(36)$ & $60(40)$ & & \\
\hline 1 impacted, 1 not impacted & $1(2)$ & $1(1)$ & & \\
\hline Tension wire size & & & $0.95(0.65-1.4)$ & 0.40 \\
\hline 16 and 18 gauge & $32(67)$ & $95(60)$ & & \\
\hline 20 and 22 gauge & $16(33)$ & $64(40)$ & & \\
\hline Number of tension wires & & & $0.87(0.47-1.6)$ & 0.76 \\
\hline Single & $41(67)$ & $116(64)$ & & \\
\hline Double & $20(33)$ & $65(36)$ & & \\
\hline Number of knot per wire & & & $1.2(0.51-2.8)$ & 0.83 \\
\hline One & $8(15)$ & $28(17)$ & & \\
\hline Two & $46(85)$ & $134(83)$ & & \\
\hline Location of knot(s) & & & $0.87(0.51-1.5)$ & 0.82 \\
\hline Lateral & $5(10)$ & $11(7)$ & & \\
\hline Medial & $1(2)$ & $4(3)$ & & \\
\hline Each side & $45(88)$ & $136(90)$ & & \\
\hline Plate type & & & $0.87(0.53-1.4)$ & 0.76 \\
\hline $\begin{array}{l}\text { Synthes precontoured (Paoli, PA, } \\
\text { USA) }\end{array}$ & $22(76)$ & $58(66)$ & & \\
\hline Acumed (Hillsboro, OR, USA) & $3(10)$ & $17(19)$ & & \\
\hline LCP (Synthes, Paoli, PA, USA) & $2(7)$ & $8(9)$ & & \\
\hline LC-DCP (Synthes) & $2(7)$ & $4(5)$ & & \\
\hline $\begin{array}{l}\text { EPS Ortholoc (Wright Medical, } \\
\text { Arlington, TN, USA }\end{array}$ & $0(0)$ & $1(1)$ & & \\
\hline Injury side & & & $0.62(0.39-0.99)$ & 0.061 \\
\hline Left & $63(64)$ & $153(52)$ & & \\
\hline Right & $36(36)$ & $140(48)$ & & \\
\hline
\end{tabular}

* According to the medical records; $\mathrm{CI}=$ confidence interval.

Table 3. Multivariable analysis-factors associated with implant removal $(\mathrm{n}=392)$

\begin{tabular}{lllr}
\hline Parameter & $\begin{array}{l}\text { Adjusted } \\
\text { odds ratio }\end{array}$ & $\begin{array}{l}\text { Adjusted 95\% } \\
\text { confidence interval }\end{array}$ & $\begin{array}{l}\text { Adjusted } \\
\text { p value }\end{array}$ \\
\hline Age per 10 years & 0.75 & $0.64-0.87$ & $<0.001$ \\
$\begin{array}{l}\text { Charlson Comorbidity } \\
\quad \text { Index }\end{array}$ & 0.89 & $0.76-1.0$ & 0.139 \\
Gender & 0.31 & $0.17-0.55$ & $<0.001$ \\
Injury side & 0.66 & $0.40-1.1$ & 0.105 \\
\hline
\end{tabular}

pullout. However, the number of reoperations and implant removal after open reduction and internal fixation of isolated olecranon fractures remains high and patient-related and fracture-related factors associated with reoperation and implant removal are incompletely understood.

The objective of this study was to investigate factors associated with reoperation and implant removal after open reduction and internal fixation of a displaced olecranon fracture that is not part of a fracture-dislocation. One-fourth of the patients requested implant removal. The most common single indication for reoperation was for implant removal, but only a small percentage of these procedures was performed for implant migration. Women and younger patients were more likely to request reoperation and implant removal. The specific surgeon and the type and configuration of the implant were not associated with implant removal. 
Table 4. Bivariate analyses-factors associated with implant removal $(n=392)$

\begin{tabular}{|c|c|c|c|c|}
\hline \multirow[t]{2}{*}{ Parameter } & \multicolumn{2}{|c|}{ Implant removal $(\mathrm{n}=92[23 \%])$} & \multirow[t]{2}{*}{ Odds ratio $(\mathrm{CI})$} & \multirow[t]{2}{*}{$\mathrm{p}$ value } \\
\hline & $\begin{array}{l}\text { Yes } \\
\text { Mean (SD) }\end{array}$ & $\begin{array}{l}\text { No } \\
\text { Mean (SD) }\end{array}$ & & \\
\hline Age (years) & $50(18)$ & $58(20)$ & $0.98(0.97-0.99)$ & $<0.001$ \\
\hline Charlson Comorbidity Index & $0.64(1.7)$ & $1.4(2.3)$ & $0.81(0.79-0.95)$ & $<0.001$ \\
\hline Experience surgeon (years) & $11(8.5)$ & $10(8.5)$ & $1.0(0.98-1.0)$ & 0.81 \\
\hline Duration (hours) & $1.3(1.6)$ & $1.4(1.1)$ & $0.94(0.73-1.2)$ & 0.62 \\
\hline \multirow[t]{2}{*}{ Plate length (cm distal to fracture) } & $6.2(1.5)$ & $6.5(1.9)$ & $0.90(0.70-1.1)$ & 0.40 \\
\hline & Number (\%) & Number (\%) & Odds ratio $(\mathrm{CI})$ & $\mathrm{p}$ value \\
\hline Gender & & & $0.57(0.35-0.92)$ & 0.023 \\
\hline Men & $33(36)$ & $151(50)$ & & \\
\hline Women & $59(64)$ & $149(50)$ & & \\
\hline Diagnosed obesity & & & $1.4(0.64-3.3)$ & 0.38 \\
\hline Yes & $9(10)$ & $21(7)$ & & \\
\hline No & $83(90)$ & $279(93)$ & & \\
\hline Smoking* & & & $1.2(0.66-2.2)$ & 0.52 \\
\hline Yes & $17(18)$ & $47(16)$ & & \\
\hline No & $75(82)$ & $253(84)$ & & \\
\hline Head injury & & & $0.80(0.29-2.2)$ & 0.81 \\
\hline Yes & $5(5)$ & $20(7)$ & & \\
\hline No & $87(95)$ & $280(93)$ & & \\
\hline Open fracture & & & $1.4(0.64-3.3)$ & 0.38 \\
\hline Yes & $9(10)$ & $21(7)$ & & \\
\hline No & $83(90)$ & $279(93)$ & & \\
\hline Other fracture & & & $0.92(0.44-1.9)$ & 1.0 \\
\hline Yes & $10(11)$ & $35(12)$ & & \\
\hline No & $82(89)$ & $265(88)$ & & \\
\hline Other fracture same limb & & & $0.55(0.22-1.3)$ & 0.24 \\
\hline Yes & $6(7)$ & $34(11)$ & & \\
\hline No & $86(93)$ & $266(89)$ & & \\
\hline Hospital & & & $1.5(0.91-2.4)$ & 0.12 \\
\hline Hospital 1 & $59(64)$ & $218(73)$ & & \\
\hline Hospital 2 & $33(36)$ & $82(27)$ & & \\
\hline Fracture type & & & $1.2(0.73-1.9)$ & 0.55 \\
\hline Mayo 2A & $51(22)$ & $177(59)$ & & \\
\hline Mayo 2B & $41(25)$ & $121(41)$ & & \\
\hline Figure of eight & $56(22)$ & & $0.80(0.49-1.3)$ & 0.38 \\
\hline Yes & $56(61)$ & $198(66)$ & & \\
\hline No & $36(39)$ & $102(34)$ & & \\
\hline Plate fixation & & & $1.3(0.78-2.1)$ & 0.38 \\
\hline Yes & $36(39)$ & $102(34)$ & & \\
\hline No & $56(61)$ & $198(66)$ & & \\
\hline Kirschner wires parallel & & & $1.2(0.57-2.3)$ & 0.72 \\
\hline Yes & $15(31)$ & $43(28)$ & & \\
\hline No & $34(69)$ & $113(72)$ & & \\
\hline Size of Kirschner wires & & & $1.1(0.55-2.4)$ & 0.86 \\
\hline 0.045 inch & $12(23)$ & $45(26)$ & & \\
\hline 0.062 inch & $40(77)$ & $131(74)$ & & \\
\hline
\end{tabular}


Table 4. continued

\begin{tabular}{|c|c|c|c|c|}
\hline & Number $(\%)$ & Number $(\%)$ & Odds ratio $(\mathrm{CI})$ & $\mathrm{p}$ value \\
\hline Angle Kirschner wires & & & $0.92(0.43-2.0)$ & 1.0 \\
\hline $\begin{array}{l}\text { Anteriorly to engage anterior } \\
\text { cortex }\end{array}$ & $33(75)$ & $113(73)$ & & \\
\hline Straight intramedullary & $11(25)$ & $41(27)$ & & \\
\hline $\begin{array}{l}\text { Kirschner wire turned } 150^{\circ} \text { and } \\
\text { impacted into the proximal ulna }\end{array}$ & & & $1.1(0.55-2.0)$ & 0.59 \\
\hline Yes & $18(39)$ & $60(39)$ & & \\
\hline No & $27(59)$ & $92(60)$ & & \\
\hline 1 impacted, 1 not impacted & $1(2)$ & $1(1)$ & & \\
\hline Tension wire size & & & $0.91(0.61-1.4)$ & 0.39 \\
\hline 16 and 18 gauge & $29(67)$ & $98(60)$ & & \\
\hline 20 and 22 gauge & $14(33)$ & $66(40)$ & & \\
\hline Number of tension wires & & & $0.84(0.45-1.6)$ & 0.64 \\
\hline Single & $38(68)$ & $119(64)$ & & \\
\hline Double & $18(32)$ & $67(36)$ & & \\
\hline Number of knot per wire & & & $1.3(0.53-3.2)$ & 0.67 \\
\hline One & $7(14)$ & $29(17)$ & & \\
\hline Two & $43(86)$ & $137(83)$ & & \\
\hline Location of knot(s) & & & $0.97(0.54-1.7)$ & 1.0 \\
\hline Lateral & $4(9)$ & $12(8)$ & & \\
\hline Medial & $1(2)$ & $4(3)$ & & \\
\hline Each side & $42(89)$ & $139(90)$ & & \\
\hline Plate type & & & $0.90(0.55-1.5)$ & 0.77 \\
\hline $\begin{array}{l}\text { Synthes precontoured (Paoli, PA, } \\
\text { USA) }\end{array}$ & $21(75)$ & $59(66)$ & & \\
\hline Acumed (Hillsboro, OR, USA) & $3(11)$ & $17(19)$ & & \\
\hline LCP (Synthes, Paoli, PA, USA) & $2(7)$ & $8(9)$ & & \\
\hline LC-DCP (Synthes) & $2(7)$ & $4(4)$ & & \\
\hline $\begin{array}{l}\text { EPS Ortholoc (Wright Medical, } \\
\text { Arlington, TN, USA) }\end{array}$ & $0(0)$ & $1(1)$ & & \\
\hline Injury side & & & $0.58(0.36-0.94)$ & 0.031 \\
\hline Left & $60(65)$ & $156(52)$ & & \\
\hline Right & $32(35)$ & 144 (48) & & \\
\hline
\end{tabular}

* According to the medical records; $\mathrm{CI}=$ confidence interval.

This study should be interpreted with its limitations in mind. The data registry is drawn from two Level I trauma centers that might not be representative of all Level I trauma centers.

We used ICD-9 and CPT codes to identify the initial diagnoses and procedures rather than review of the medical records. ICD-9 and CPT codes could be miscoded. We may have had insufficient power to detect small but important differences related to implant choice and configuration. Lastly, this study design is retrospective, which makes it inherently more susceptible to data loss, bias, and confounding than a prospective study. For example, in 189 patients, the followup was less than one year.
Women and younger patients were more likely to have a reoperation for any reason and more likely to request implant removal specifically. Consistent with our results, prior research found infection, implant failure, and symptoms related to the implants were the most common reasons for reoperation $[9,15]$. Our study found that personal rather than technical or injury factors had the greatest influence on requests for implant removal. Only 12 implants (3\%) in our study were removed as a result of migration or loosening. Implant removal was mostly discretionary. Contrary to our findings, Saeed and colleagues [20] found that reoperation and implant removal were more common with age and thought this might be related to fixation problems in 
osteoporotic bone. It is not clear why this difference was observed. The mean age was similar to the age in our cohort. Their cohort was smaller than ours and they only included patients with tension band wire fixation.

Women and younger patients were more likely to have a second operation or request or accept the offer of implant removal no matter the type of implant and the technical variations. In an attempt to understand our findings, we posit that women-younger women in particular-might have smaller elbows and less subcutaneous fat leading to more bothersome implants. On the other hand, they might simply prefer to remove the implants more than older patients and men. The selection of method of fixation should be based on the treatment of the fracture. Patients who have operative fixation of a fracture of the olecranon can be counseled that most patients keep their implants, that only $3 \%$ experience implant migration, and that technical factors such as the type or configuration of an implant seem less important than personal factors in determining who requests a second surgery for implant removal.

\section{References}

1. Argintar E, Cohen M, Eglseder A, Edwards S. Clinical results of olecranon fractures treated with multiplanar locked intramedullary nailing. J Orthop Trauma. 2013;27:140-144.

2. Argintar E, Martin BD, Singer A, Hsieh AH, Edwards S. A biomechanical comparison of multidirectional nail and locking plate fixation in unstable olecranon fractures. J Shoulder Elbow Surg. 2012;21:1398-1405.

3. Assom M, Lollino N, Caranzano F, Rossi R, Castoldi F. Polyester tension-band wiring of olecranon fractures of elderly people: a simple technique. Injury. 2008;39:1474-1476.

4. Carofino BC, Santangelo SA, Kabadi M, Mazzocca AD, Browner BD. Olecranon fractures repaired with FiberWire or metal wire tension banding: a biomechanical comparison. Arthroscopy. 2007;23:964-970.

5. Chen W, Zhang Q, Hou Z, Zhang Y. The application of central tension plate with sharp hook in the treatment of intra-articular olecranon fracture. BMC Musculoskelet Disord. 2013;14:308.

6. Gordon MJ, Budoff JE, Yeh ML, Luo ZP, Noble PC. Comminuted olecranon fractures: a comparison of plating methods. $J$ Shoulder Elbow Surg. 2006;15:94-99.

7. Haddad B, Khan W, Zaghloul A, Grimes L, Schenk W. Fixation of olecranon fractures and osteotomies using compression screws: a simple solution to a common problem. A study of cases. Ortop Traumatol Rehabil. 2013;15:341-346.

8. Hume MC, Wiss DA. Olecranon fractures. A clinical and radiographic comparison of tension band wiring and plate fixation. Clin Orthop Relat Res. 1992;285:229-235.

9. Ishigaki N, Uchiyama S, Nakagawa H, Kamimura M, Miyasaka T. Ulnar nerve palsy at the elbow after surgical treatment for fractures of the olecranon. J Shoulder Elbow Surg. 2004;13:60-65.

10. Jones TB, Karenz AR, Weinhold PS, Dahners LE. Transcortical screw fixation of the olecranon shows equivalent strength and improved stability compared with tension band fixation. J Orthop Trauma. 2014;28:137-142.

11. Kim JY, Lee YH, Gong HS, Lee SL, Lee SK, Baek GH. Use of Kirschner wires with eyelets for tension band wiring of olecranon fractures. J Hand Surg Am. 2013;38:1762-1767.

12. Lalliss SJ, Branstetter JG. The use of three types of suture and stainless steel wire tension banding for the fixation of simulated olecranon fractures: a comparison study in cadaver elbows. $J$ Bone Joint Surg Br. 2010;92:315-319.

13. Lalonde JA Jr, Rabalais RD, Mansour A, Burger EL, Riemer BL, $\mathrm{Lu}$ Y, Baratta RV. New tension band material for fixation of transverse olecranon fractures: a biomechanical study. Orthopedics. 2005;28:1191-1194.

14. Larsen E, Jensen CM. Tension-band wiring of olecranon fractures with nonsliding pins. Report of 20 cases. Acta Orthop Scand. 1991;62:360-362.

15. Lindenhovius AL, Brouwer KM, Doornberg JN, Ring DC, Kloen P. Long-term outcome of operatively treated fracture-dislocations of the olecranon. J Orthop Trauma. 2008;22:325-331.

16. Morrey BF, Adams RA. Fractures of the proximal ulna and olecranon. Elbow and Its Disorders. 1993:405-428.

17. Mullett JH, Shannon F, Noel J, Lawlor G, Lee TC, O'Rourke SK. $\mathrm{K}$-wire position in tension band wiring of the olecranon-a comparison of two techniques. Injury. 2000;31:427-431.

18. Prayson MJ, Williams JL, Marshall MP, Scilaris TA, Lingenfelter EJ. Biomechanical comparison of fixation methods in transverse olecranon fractures: a cadaveric study. J Orthop Trauma. 1997;11:565-572.

19. Quan H, Li B, Couris CM, Fushimi K, Graham P, Hider P, Januel JM, Sundararajan V. Updating and validating the Charlson comorbidity index and score for risk adjustment in hospital discharge abstracts using data from 6 countries. Am J Epidemiol. 2011;173:676-682.

20. Saeed ZM, Trickett RW, Yewlett AD, Matthews TJ. Factors influencing K-wire migration in tension-band wiring of olecranon fractures. J Shoulder Elbow Surg. 2014;23:1181-1186.

21. Tarallo L, Mugnai R, Adani R, Capra F, Zambianchi F, Catani F. Simple and comminuted displaced olecranon fractures: a clinical comparison between tension band wiring and plate fixation techniques. Arch Orthop Trauma Surg. 2014;134:11071114. 